\title{
Teacher assessments could replace high- stake testing to improve student well-being
}

\author{
By Jessica K. Edwards
}

Children in the UK must complete numerous standardized school exams and teacher-based assessments during their compulsory education. Despite the known benefits of testing in terms of consolidating and fostering learning, there are many known downsides to regular testing. For example, many students experience anxiety and distress during exams, and these emotions can have a negative effect on achievement. Notably, one of the top-reported concerns voiced by children in the UK is the stress and anxiety associated with school work and exam performance. ${ }^{1}$

Now, Kaili Rimfeld and colleagues have assessed the cost-benefit ratio for standardized exams and teacher assessments in school-age children. They examined the phenotypic and genetic associations between teacher assessments and standardized exam scores at ages 7,11 and 14, and then assessed the extent to which standardized test scores add to teacher assessments and help predict educational achievement in key subjects at ages 16 and 18 . Their study included $>5,000$ twin pairs enrolled in the UK-representative Twins Early Development Study who were studied longitudinally from age 7 to 18 . They found that teacher assessments of achievement were as reliable, stable and heritable $(\sim 60 \%)$ as test scores at every stage of education. Furthermore, teacher and exam test scores showed a strong correlation both phenotypically and genetically ( 0.7). Most notably, teacher assessments predicted $\sim 90 \%$ of the differences between pupils in exam performance at ages 16 and 18 .
The researchers consider that their data might inform the debate on the use of high-stake examining during compulsory school education in the UK. Specifically, the high correlation between teacher assessments and test scores raises the question as to the value of compulsory testing in the UK, culminating in high-stake exams at age 16 (GCSEs) and 18 (A-levels). Because of the various costs of high-stake examining, the researchers promote the standardization and wider use of teacher assessments and a reduction in testing to help improve student well-being.

\section{Referring to:}

Rimfeld, K., Malanchini, M., Hannigan, L.J., Dale, P.S., Allen, R., Hart, S.A. \& Plomin, R. (2019),

Teacher assessments during compulsory education are as reliable, stable and heritable as standardized test scores. J. Child Psychol. Psychiatr. doi: 10.111/ jcpp.13070.

\section{See also: www.teds.ac.uk/}

\section{References:}

${ }^{1}$ NSPCC (2015) Under pressure: Childline annual review 2013/2014. London: NSPCC. 